\title{
$\beta$-Defensin 22 is a major component of the mouse sperm glycocalyx
}

\author{
Ashley I Yudin ${ }^{1}$, Theodore L Tollner ${ }^{1}$, Cathy A Treece ${ }^{1}$, Robert Kays ${ }^{2}$, Gary N Cherr ${ }^{3,4}$, \\ James W Overstreet ${ }^{1}$ and Charles L Bevins ${ }^{2}$ \\ ${ }^{1}$ Center for Health and the Environment, ${ }^{2}$ Department of Microbiology and Immunology, School of Medicine, \\ ${ }^{3}$ Departments of Environmental Toxicology and Nutrition, University of California, Davis, California 95616, USA and \\ ${ }^{4}$ Bodega Marine Laboratory, University of California Davis, PO Box 247, Bodega Bay, California 94923, USA \\ Correspondence should be addressed to G N Cherr; Email: gncherr@ucdavis.edu
}

\begin{abstract}
Surface components of sperm isolated from the cauda epididymides were stabilized by whole sperm fixation for immunization of rabbits. The resulting immunoglobulins (Igs) recognized a single protein of $130 \mathrm{kDa}$ (non-reduced) or 54-57 kDa (reduced) on western blots of cauda sperm. Igs recognized the same 54-57 kDa protein band on whole tissue blots of the corpus and cauda epididymidis and vas deferens. No immunoreactive bands were detected on blots of the prostate, seminal vesicles, testes, caput epididymis, or any of various non-reproductive tissues. Removal of sperm from the vas deferens prior to blotting eliminated the detection of the sperm antigen. Antibodies raised to synthetic peptides, identical in amino acid sequence to two unique spans of DEFB22, recognized the same 130/54-57 kDa antigen on western blots of both caudal sperm and the purified antigen isolated with the anti-sperm Ig. From indirect immunofluorescence, both the anti-sperm and anti-peptide Igs appeared to localize to the entire sperm surface, a pattern confirmed at the ultrastructural level. Real-time PCR identified the corpus epididymides as the major site of expression of DEFB22, with negligible expression in the testes, caput epididymides, and vas deferens. Immunostaining of epididymal sections showed DEFB22 being released into the lumen at the distal caput/proximal corpus, with sperm becoming intensely coated with DEFB22 as they reached the distal corpus. Most uterine sperm recovered from mice $4 \mathrm{~h}$ following copulation exhibited DEFB22 coating the entire sperm surface. By contrast, some sperm recovered from the oviduct and cumulus extracellular matrix showed loss of DEFB22 from the sperm head.
\end{abstract}

Reproduction (2008) 136 753-765

\section{Introduction}

Mammalian spermatozoa exit the testes as highly differentiated, but functionally incompetent cells (Yanagimachi 1994). The sperm must undergo a secondary stage of development termed 'sperm maturation' before they initiate motility and become capable of fertilization (Cooper 1986). The acquisition of motility and the potential to fertilize an egg, coupled with lipid membrane stabilization and surface protection, are attained by sperm during transit through the various regions of the epididymis (Cooper 1986, Bedford 1990, Yanagimachi 1994). The phenomenon of sperm maturation is viewed primarily as a membrane or surface event (Turner 1995, Cooper 1998). A host of alterations to the plasma membrane has been reported to occur in the different regions of the epididymis, and these include enzymatic modifications and/or adsorption of masking molecules (Hinton \& Palladino 1995). Each of the functions acquired during epididymal transport may be directly related to the epididymal secretions and their effect on the sperm plasma membrane (Cooper 1998, Jones 1998). The epididymis is a very long and highly convoluted tube that is separated into at least three major anatomical structures (caput, corpus, and cauda), but recently the mouse epididymis was further dissected into at least ten sub-segmental regions based on discrete patterns of gene expression (Johnston et al. 2005, Oh et al. 2006). Of the three major anatomical regions, the caudae epididymides have been designated as the sperm storage site and primarily function to keep sperm compacted together and in a protected quiescent state (Hinton et al. 1996, Jones 1999). The caput and corpus regions thereby become the principal sites of the sperm maturation process (Cooper 1998). Of the four different cell types that line the intralumen of the epididymis, the principal cells are considered the primary secretory cells and are thought to control the complex microenvironment that sperm traverse before deposition and storage in the caudae epididymides (Hinton \& Palladino 1995, Moore 1998, Dacheux et al. 2003).

One of the crucial functions of the epididymis is the establishment of a surface glycocalyx that accumulates and encapsulates the entire sperm (Schroter et al. 1999). The functions of the glycocalyx may involve membrane 
stabilization, sperm survival, and control of capacitation, as well as transport in the female reproductive tract (Bedford 1975, Cooper 1986, Jones 1998, Tollner et al. 2008a, 2008b). While there have been hundreds of epididymal secretory products reported, only a handful has been shown to be integrated or adsorbed onto the sperm surface (Dacheux et al. 2003, Oh et al. 2006). One secretory product, $\beta$-defensin 126 (DEFB126; also termed epididymal secretory protein (ESP) 13.2), coats the entire surface of cynomolgus macaque sperm and is a dominant component of the sperm glycocalyx (Yudin et al. 2003, 2005b). Furthermore, DEFB126 is involved in a number of physiological events, including sperm penetration of cervical mucus, sperm capacitation, and sperm binding to the oviductal epithelium (Tollner et al. 2004, 2008a, $2008 b$ ). The $\beta$-defensins are a large family of antimicrobial peptides, many of which have antibiotic and/or chemotactic activities and almost all are found within the male reproductive tract (Patil et al. 2005, Oh et al. 2006). $\beta$-Defensin 126 has an extended carboxyl region that is highly glycosylated with terminal sialic acids that form the negative shell around the sperm (Yudin et al. 2005a, 2005b). To determine whether the mouse sperm surface possess a similarly uniform surface coat, we employed the same technique used previously in monkeys, and immunized rabbits with whole fixed mouse sperm (Yudin et al. 2005a). We report that $\beta$-defensin 22 (DEFB22), a $\beta$-defensin 126 orthologue, is synthesized in the murine corpora epididymides and coats mature sperm. Our data support the hypothesis that in mice, and also in monkeys, this molecule may be involved in sperm transport within the male and female.

\section{Results}

Historically, whole sperm injections have been used successfully to elicit an immune reaction to surface molecules, so that identification, localization, and function could be more clearly discerned (Lopo \& Vacquier 1980, Vernon et al. 1982, Gaunt 1983). Recently, the use of fixed macaque sperm at different stages of capacitation yielded interesting results. When noncapacitated fixed macaque sperm were used as the immunogens, rabbits produced antibodies primarily to a single glycopeptide, $\beta$-defensin 126 (Yudin et al. 2005a). Using this approach, noncapacitated mouse sperm released from the cauda epididymidis or the vas deferens elicited a consistent single immunorecognition in all of the whole fixed sperm immunizations (Fig. 1). Four separate rabbits were immunized with fixed mouse sperm (FMS), two receiving fixed cauda sperm and two receiving fixed vas deferens sperm, and all gave a very similar immune response (data not shown). The western blot of whole cauda sperm before and after chemical reduction showed immunorecognition to a single 130/ 54-57 kDa (non-reduced/reduced) antigen (Fig. 1B and F). In order to confirm that the single recognized antigen
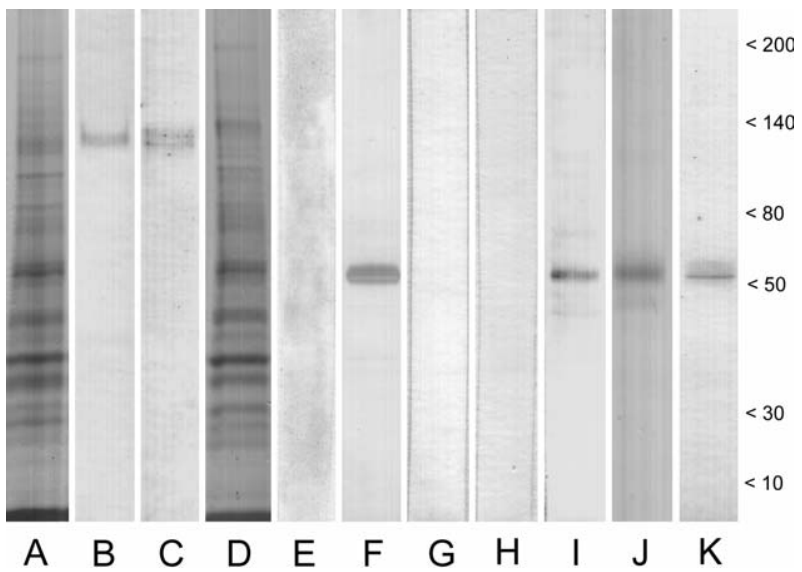

Figure 1 Cauda epididymidis sperm were solubilized in non-reducing and reducing buffer before being electrophoretically separated on an 8-16\% gel and stained with GelCode Blue for identification of proteins (A and D). The same sperm preparation when blotted to nitrocellulose and then probed with anti-FMS Ig and/or anti-DEFB22 peptide Ig show the same labeling pattern (B,C,F, I, and $K)$. The non-reduced sperm preparation had the DEFB22 antigen as $130 \mathrm{kDa}$ (B and C), but after chemical reduction it had an electrophoretic mobility of 54-57 kDa (E and I). Isolation of the FMS antigen over an anti-FMS Ig column gave a pure 54-57 kDa band when stained with GelCode Blue $(J)$ and the resulting western blot was recognized by the anti-DEFB22 peptide $\lg (\mathrm{K})$.

was in fact DEFB22, polyclonal antibodies were developed to two regions along the DEFB22 molecule. The amino acid sequence of DEFB22 is shown with bracketed residues indicating the peptide sites synthesized for antibody production (Fig. 2).

Antibodies to the two DEFB22 synthetic peptides recognized a protein band at both the 130 and 54-57 kDa regions on western blots of the same cauda epididymal sperm used in prior blots probed with antibodies generated to whole sperm (Fig. 1C and I). No sperm proteins are recognized when blots are probed with preimmune sera from rabbits later immunized with FMS (Fig. 1E) or DEFB22 synthetic peptides (Fig. 1G). Blots probed with DEFB22 synthetic peptide together with anti-DEFB22 antibody show no recognition of sperm proteins (Fig. $1 \mathrm{H}$ ). Purification of the FMS antigen showed a protein with similar molecular weight (54-57 kDa; Fig. 1J), which when probed after western blotting with anti-DEFB22 synthetic peptides recognized the same 54-57 kDa FMS protein (Fig. 1K).

Samples from a variety of mouse tissues were solubilized in reducing buffer before electrophoresis. Proteins from the following tissue lysates - bladder, small intestine, kidney, liver, lung, lymphatic, pancreas, spleen, heart, and muscle - from both males and females were separated on $8-16 \%$ gels and stained with GelCode Blue for visualization (Fig. 3A, 1-10). A western blot revealed no immunorecognition of any of the mouse tissue proteins examined (Fig. 3B, 1-10). Extracts of the caudae epididymides from two other rodents, rat and hamster, showed no crossreactivity with the mouse anti-FMS Ig and anti-DEFB22 Ig, 


\section{GWYVKKCANTLGNCRKMC\{RDGEKQTEPATSK\}CPIGKLCCVLDFKISGHCG \{GG GQNSDNLVTAGGDEGSS \} AKASTAAMVGAAAMAGTPTKTSAPAKTSAPAKTSTT TKANNAAKA $\underline{S T T T K A S N A A K A} \underline{S} A A T M A G N T T K V \underline{S T A A I A S T P A Q A} \underline{S T P} \underline{T}$ KAN $\underline{S T}$}

Figure 2 Primary amino acid sequence of mature mouse DEFB22 deduced from the mRNA nucleotide sequence (GenBank accession no. AK078980). The $\beta$-defensin domain is shown with the grey shading and the canonical six cysteine arrays are highlighted with black C's. The two amino acid stretches that were chemically synthesized and used as antigens are enclosed within the brackets. Serine and threonine residues that may serve as sites of $O$-linked glycosylation are underlined. The predicted 20 amino acid signal sequence at the amino terminus is not shown.

but the mouse vas deferens had a broad 54-57 kDa band (Fig. 3B, 11-13). Two male reproductive secretory organs, prostate and seminal vesicle, secrete a copious amount of material at the time of ejaculation, but neither tissue was recognized by antibodies to DEFB22 (Fig. 4A and B, 1, 2). The same held true for the testis and caput epididymidis, which showed no sign of immunorecognition (Fig. 4A and $B, 3,4)$. The corpus epididymidis was the initial site in which DEFB22 became recognizable and it appeared as a single band on a western blot (Fig. 4B, 5). The caudal epididymis also showed a single broad band, 54-57 kDa (Fig. 4B, 6). The vas deferens also showed a strong immune reaction to a single 54-57 kDa band, but if the sperm were removed from the vas deferens duct, DEFB22 immunorecognition was lost (Fig. 4B, 7, 8). Prior to copulation the uterine tissue was not recognized by anti-DEFB22 Igs, but uteri obtained from mated females exhibited a prominent band at the 54-57 kDa range, which is consistent with the presence of sperm (Fig. 4B, 9, 10).

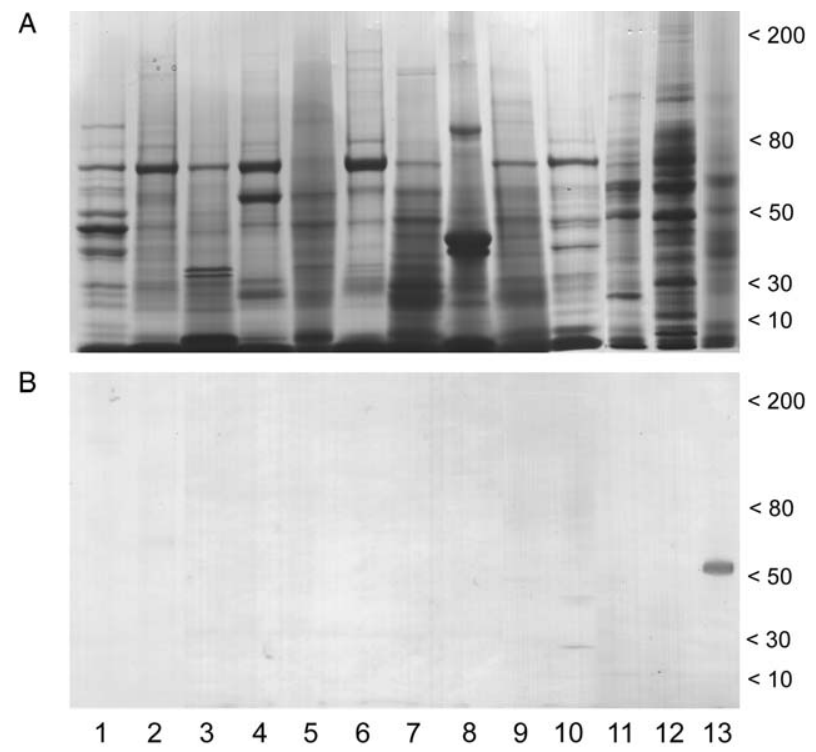

Figure $3 \mathrm{~A}$ variety of tissues were solubilized and electrophoresed on an $8-16 \%$ gel and stained with GelCode Blue (A) and all of the same samples were western blotted (B). The selected tissues included bladder (1), small intestine (2), kidney (3), liver (4), lung (5), lymphatic (6), pancreas (7), spleen (8), heart (9), muscle (10), rat vas deferens (11), hamster vas deferens (12), and mouse vas deferens (13). In all the samples, only the mouse vas deferens had immunorecognition of the 54-57 kDa region with anti-FMS Ig (13).
An immunohistological examination of the proximal corpus epididymidis revealed numerous cross-sectional views of the highly convoluted nature of the duct (Fig. 5A). While the epididymis has been divided into three gross anatomical regions, caput, corpus, and cauda, each region was further subdivided into individual segments that are known to have unique protein expression patterns (Johnston et al. 2005). Exactly where the caput ended and the corpus began was not easily discerned, but it would appear that there was

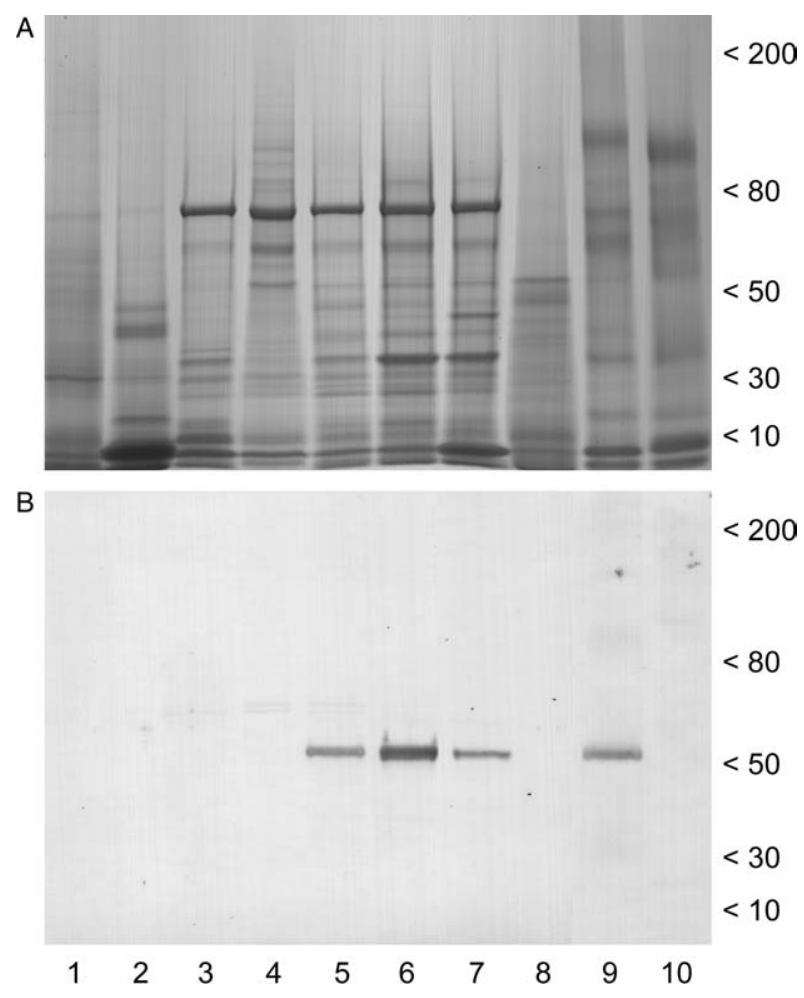

Figure 4 The electrophoretic profile of the prostate (1), seminal vesicles (2), testis (3), caput epididymidis (4), corpus epididymidis (5), cauda epididymidis (6), vas deferens (7), vas deferens without sperm (8), uterus after mating (9), and uterus before mating (10). The gel was stained with GelCode Blue. When the reproductive tissues were blotted onto nitrocellulose and probed with anti-FMS Ig, the prostate, seminal vesicle, testis, and caput epididymidis showed no cross reactivity (B:1-4). The corpus, caudal epididymis, and vas deferens all had a prominent band at the 54-57 kDa region (B:5-7). While anti-FMS Ig recognized vas deferens $(B: 7)$, the recognition was no longer observed after sperm were removed (B:8). A similar situation was observed for the uterus, where the post-coital uterus had a prominent band at $54-57 \mathrm{kDa}$ (B:9), which was absent if the female had not been mated (B:10). 

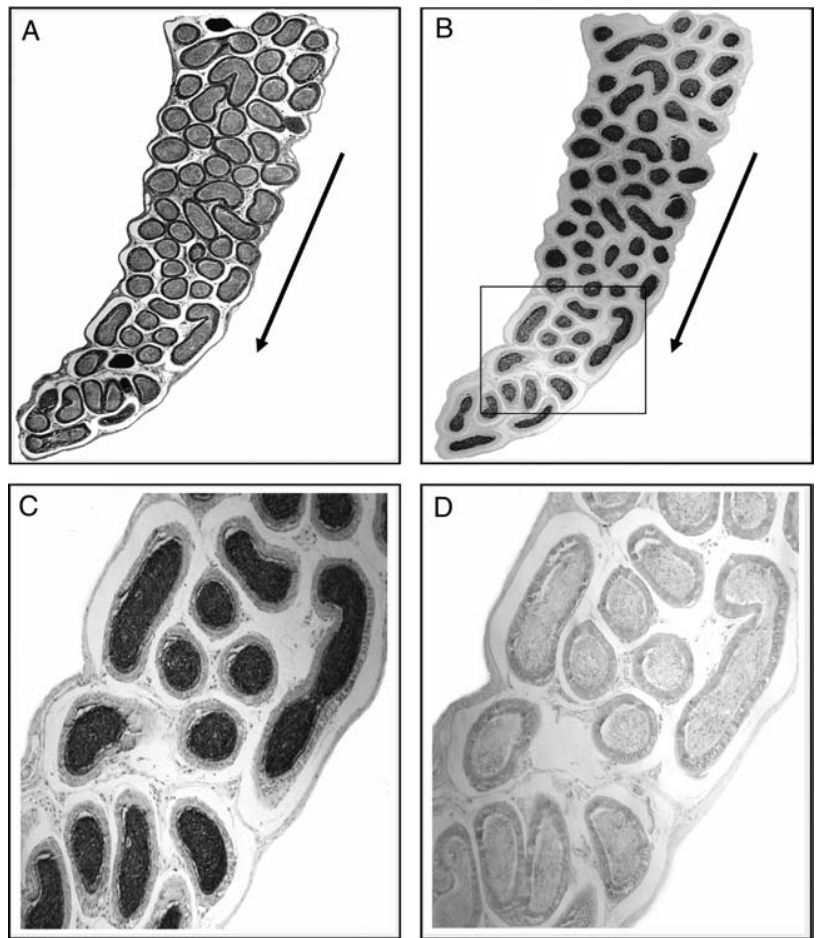

Figure 5 Localization of FMS antigen (DEFB22) on $6 \mathrm{~m}$ thick paraffin sections of the corpus portion of the mouse epididymis from the most proximal to the most distal region just before entering the cauda epididymidis. The proximal corpus is the initial site of immunorecognition of DEFB22. A composite picture of the entire corpus epididymides is shown after staining with Papanicolaou and the numerous cross sections through the duct show the convoluted nature of the epididymis (A). The arrows point from the proximal to the distal regions (A). (B) The same or the next set of sections but after exposure to anti-FMS, which clearly shows the ducts to be intensely labeled (B). A higher magnification of the boxed area clearly shows a lack of label within the epididymal cells and tissue, but the lumen as noted before is intensely labeled (C). The next section was labeled with preimmune FMS serum and did not show any signs of label (D).

immunorecognition of DEFB22 at the portion of the corpus that merges with the caput (Fig. 5B). The duct was highly coiled and lined with columnar cells (Fig. 5A), but immunoreactivity to DEFB22 was confined to the luminal surface of the duct and the lumens content (Fig. 5A and B). The proximal corpus showed divided segmentation, but for most of the parts the intraluminal components showed strong immunoreaction to antiDEFB22 and were most intense as the lumen became swollen with sperm (Fig. 5C). A preimmune serum control staining of the same corpus region showed no immunorecognition (Fig. 5D).

Higher magnification images at the juncture of the caput and proximal corpus showed that the columnar cells lining the lumen exhibited an array of stereocilia along the apical border (Fig. 6A). The apical border with the stereocilia are highly immunoreactive to antiDEFB22 (Fig. 6B). Directly below the apical membrane there was labeling of the DEFB22, but this label did not appear in other regions of the cells (Fig. 6B). The sperm found within the lumen also showed some labeling, but the luminal matrix surrounding the sperm did not show immunorecognition to anti-DEFB22 (Fig. 6B). A fine structural view of this region clearly shows the luminal matrix, the stereocilia extending from the apical surface of the epididymal cells and the sperm embedded within the matrix (Fig. 6C). The region directly opposed to the stereocilia and just below the apical membrane possessed an abundance of small vesicles and their location corresponds to the labeling found with antiDEFB22 (Fig. 6B and C).

To determine the pattern of Defb22 mRNA expression in reproductive tissues, we employed quantitative realtime RT-PCR of RNA from specific tissues (Fig. 7). Expression levels were normalized to total input RNA for each reaction (10 ng) and absolute mRNA copy numbers were determined using gene-specific standard curves. There was negligible Defb22 expression in the testes, caput, and vas deferens (less than 100 copies per $10 \mathrm{ng}$ RNA), and very low expression in the cauda $(\sim 400$ copies/10 ng total RNA). By contrast, highly abundant Defb22 mRNA expression $(\sim 7 \times 104$ copies/10 ng total RNA) was detected specifically in the corpus (Fig. 7). The housekeeping gene $\beta$-actin was also analyzed for all tissue samples as a control for RNA integrity and efficiency of RT reaction in each sample (Fig. 7).

Sperm from the caudal epididymis and/or the vas deferens were fixed upon release from the ruptured ducts and examined for presence of DEFB22. Immunorecognition with the polyclonal antibody to anti-FMS revealed a bright fluorescent label of goat anti-rabbit (GAR)-Alexa 488 over the entire sperm cell (Fig. 8A). While all regions of the sperm surface had labeling for DEFB22, the equatorial segment was clearly less intense (Fig. 8A). The sperm all appeared to be acrosome intact, when viewed with phase microscopy (not shown). The same sperm sample was also exposed to anti-DEFB22 peptide, which gave a very similar fluorescent pattern as seen with anti-FMS (Fig. 8B).

At the fine structural level, the gold label closely reflected what was observed at the fluorescence level (Fig. 8C). Gold particles were found along each of the five morphologically unique regions of the sperm (Fig. 8C). The flagellum, posterior head, and acrosome each had a very similar dispersion of gold particles, while the equatorial segment had less gold distribution along the surface (Fig. 8C). The gold labeling at the fine structural level was very close to the pattern noted at the fluorescent level (Fig. 8A-C). A higher magnification of a cross-sectional view of the sperm head clearly demonstrated the gold labeling of the plasma membrane covering the acrosome (Fig. 8D).

DEFB22 distribution on sperm within the female reproductive tract was examined by looking at the sperm from the uterus, oviduct, and the oocyte-cumulus complexes collected $4 \mathrm{~h}$ after mating. A total of five females were examined, each with similar results. 

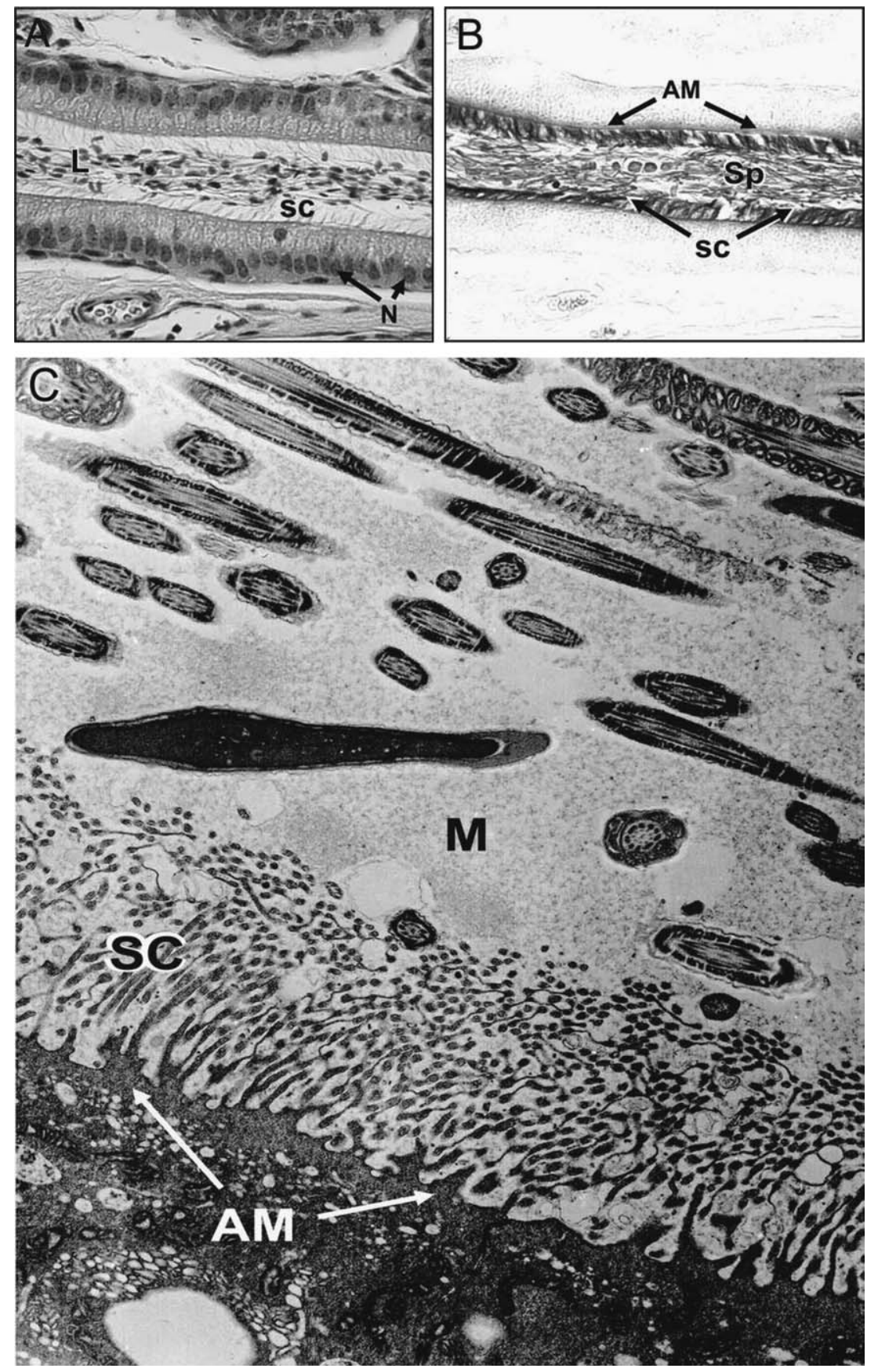

Figure 6 A closer examination at higher magnification of the proximal corpus and the initial site of DEFB22 recognition. (A) A longitudinal section through a duct within the proximal corpus which shows the epithelium having an array of stereocilia (SC) protruding into the sperm-filled lumen (L). All of the nuclei $(\mathrm{N})$ of the columnar epithelium are located in the opposing surface of the cell away from the apical membrane (A). (B) The following section, which shows anti-FMS Ig (DEFB22) clearly labeled as the stereocilia (SC) and the cell components just below the apical membrane (AM). There was a noticeable label on the sperm (Sp) found within the lumen and directly below the apical membrane. At the fine structural level (C), the proximal corpus clearly illustrates the extensive layer of stereocilia (SC). The sperm were embedded within a matrix $(M)$ that did not label with the anti-FMS Ig. The region just below the apical membrane (AM) is filled with small vesicles and this region was recognized by the anti-FMS Ig (C).
All females had an abundance of highly motile sperm within the uterus, and the sperm were embedded within a milky matrix. All of the sperm were fixed after suspension in the media, and all of the sperm exhibited immunorecognition of DEFB22 over the entire surface, although many sperm had less intense labeling over the equatorial region (Fig. 9A-C). Immunofluorescent patterns were similar to those observed for a caudal or vas deferens sperm (Fig. 9A-C). The view of the entire sperm showed immunorecognition from the apical acrosome to the tip of the flagellum (Fig. 9C). The sperm located in the oviduct showed immunorecognition of DEFB22 over the entire surface as noted in the uterus, but some sperm were occasionally found to have lost labeling from over the equatorial region while other sperm exhibited complete loss over the acrosome (Fig. 10A-C). Some sperm had already entered the oocyte-cumulus complex, but no fertilization was observed. The sperm appeared to be confined to the surface of the cumulus matrix or were partially embedded in it (Fig. 11A-C). The sperm found on the cumulus surface showed immunoreactivity to DEFB22 along the entire sperm surface with the brightest 


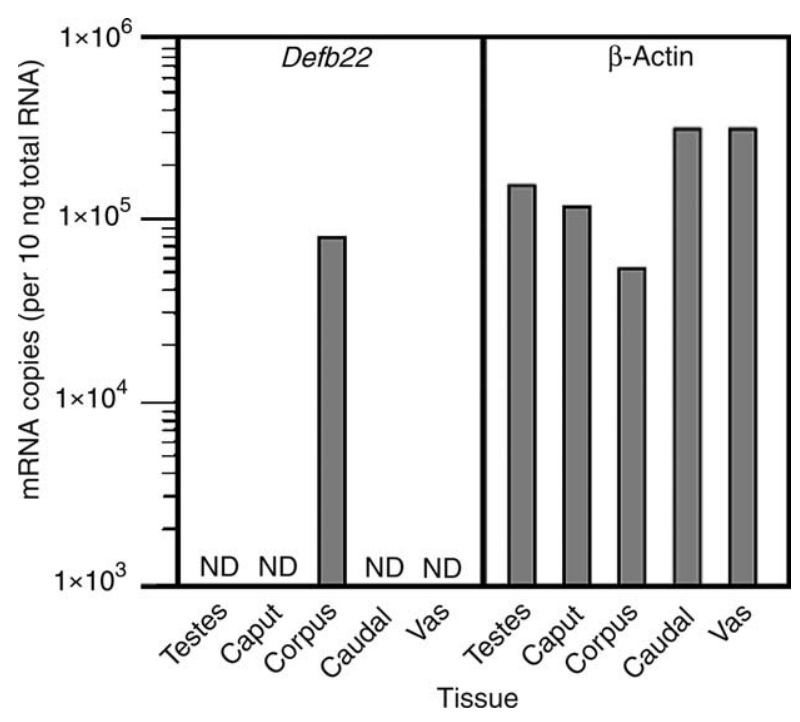

Figure 7 Quantitative real-time PCR analysis is shown for Defb22 mRNA expression in the mouse male reproductive tract. Samples of five male reproductive tract tissues (testes, caput, corpus, cauda, and vas deferens) were pooled from three separate BDF1 mice. For each tissue sample, total RNA was isolated, reverse transcribed into cDNA, and an aliquot of the cDNA product (corresponding to $10 \mathrm{ng}$ RNA) was used as a template for real-time PCR analysis with specific primers (Table 1). The corpus epididymis was clearly the highest in Defb22 expression, while the other regions of the male reproductive tract had nondetectable level. The mRNA copy counts were determined in duplicate from a standard curve as described in the methods. As a control, $\beta$-actin mRNA levels were similarly determined for each tissue sample.

fluorescence along the apical acrosome of the sperm head (Fig. 11A and B). Those sperm found within the cumulus matrix had lost most of the immunofluorescence over the sperm head, but label was still detected along the midpiece and flagellum (Fig. 11C).

\section{Discussion}

There is a significant glycocalyx on sperm when they are ejaculated, and the systematic removal or modification of this glycocalyx within the female reproductive tract is at least a major component of the phenomenon known as capacitation (Chang \& Pincus 1951, Piko 1969, Harrison 1996, Schroter et al. 1999). The mechanisms involved in epididymal maturation and capacitation of sperm are still being actively investigated and many of the pieces to the puzzle remain elusive (Jaiswal \& Eisenbach 2002). One glycoprotein that has been shown to cover the entire surface of macaque sperm is DEFB126, a $\beta$-defensin, which has an extensive carboxyl tail region with many O-linked carbohydrates (Yudin et al. 2003, 2005b). The orthologue of DEFB126 ( $\beta$-defensin 22) is also found on rat sperm (Rao et al. 2003, Zanich et al. 2003). When antibodies were developed in rabbits to whole fixed ejaculated macaque sperm there was an extensive immune response, but only to a single sperm antigen (32-36 kDa; Yudin et al. 2005a). Virtually, the same
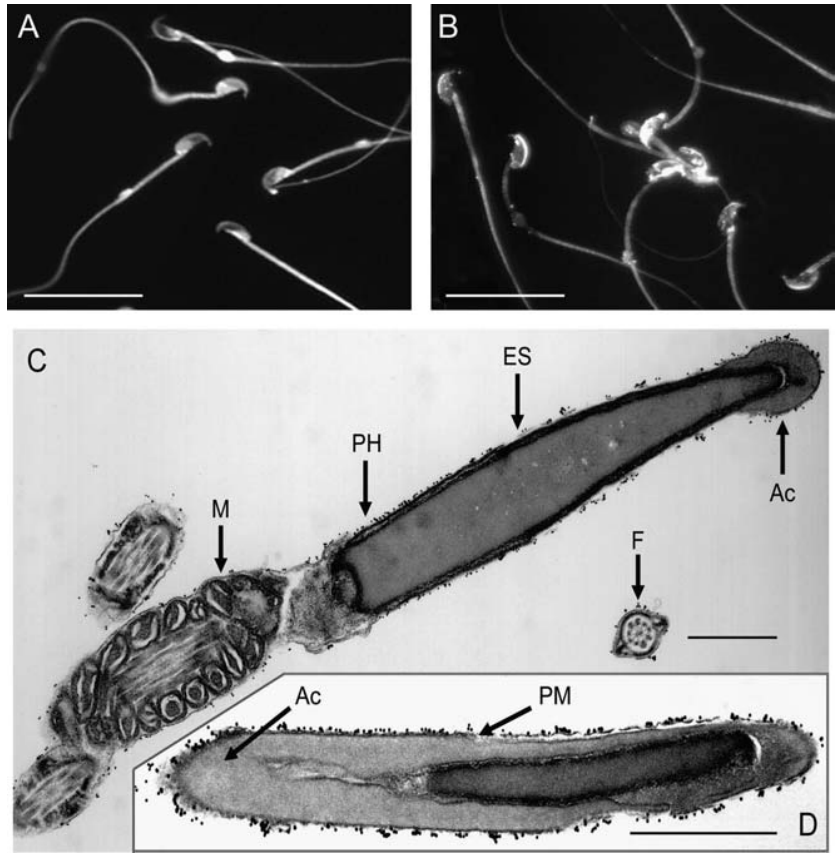

Figure 8 (A) Immunolocalization of FMS (DEFB22) on cauda epididymidis sperm fixed directly after release into the medium. When fixed, cauda sperm incubated with anti-FMS Ig and exposed to goat anti-rabbit Alexa 488, the entire sperm showed some level of fluorescence, although there was a slightly less intensity over the equatorial segment. (B) The same labeling pattern was exhibited when anti-DEFB22 peptide Ig was used. $\mathrm{Bar}=30 \mu \mathrm{m}$. Control sperm incubated with preimmune serum had no immunofluorescence (not shown). (C) Immunolocalization at the fine structural level revealed a layer of goat anti-rabbit gold particles dispersed along the entire sperm surface. The flagellum $(\mathrm{F})$, posterior head $(\mathrm{PH})$, equatorial segment (ES), and the acrosomal cap (A) had labeling along the plasma membrane. (D) A higher magnification of the most anterior acrosomal region of the sperm head clearly showed the uniform distribution of the gold particles (DEFB22) over the acrosomal portion of the sperm head. Bar $=0.5 \mu \mathrm{m}$ (in C and D).

technique was used in the present study, except that FMS from the caudal epididymis or vas deferens were used as the antigen. Immunization of rabbits resulted in a similarly restricted immune reaction to a single broad band $(130 / 54-57 \mathrm{kDa})$ in preparations of mouse sperm. These findings have led us to conclude that sperm of these species have DEFB126/DEFB22 as their most exterior component of the glycocalyx (Rao et al. 2003, Yudin et al. 2005a).

Previous studies have shown that monoclonal antibodies developed from sperm iso-antigens (SMA4, T21, TSC4) recognize a coat that extends along the surface of mouse sperm (Feuchter et al. 1981, Vernon et al. 1982, Okabe et al. 1986, Toshimori et al. 1988). The anti-SMA4 and T21 antibodies are more than likely in recognizing a common antigen on the mouse sperm flagellum, while the anti-TSC4 antibody also recognizes components along the sperm head (Okabe et al. 1987, Feuchter et al. 1988, Toshimori et al. 1988, 1990). Toshimori et al. (1988) reported that the sialic acid associated with the T21 antigen was critical for creating 

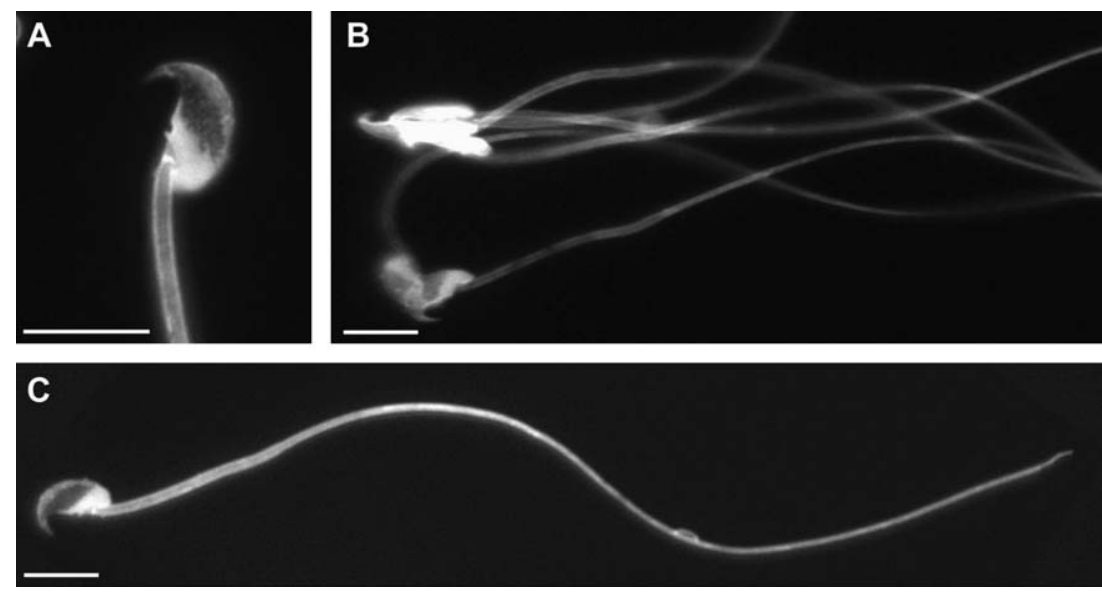

Figure 9 Mouse sperm were flushed from the uteri of mated females at $4 \mathrm{~h}$ post-coitus and fixed before incubation with anti-FMS Ig and secondary labeling with goat anti-rabbit Alexa 488. The sperm had detectable fluorescence from the tip of the acrosomal cap to the tip of the flagellum, although the equatorial segment did show a decreased level of fluorescence (A-C). The sperm found within the uterus were often in various degrees of clumping, but there were ample individual, free swimming sperm. In all cases, sperm found within the uterus at $4 \mathrm{~h}$ post-coitus had labeling over the entire sperm (A-C).

Bar $=1 \mu \mathrm{m}$. Preimmune controls showed no fluorescence (not shown).

the negative charge of mouse sperm, thereby masking the antigenic determinants on the sperm surface, a phenomenon also thought to be involved in the protection of macaque sperm by DEFB126 (Yudin et al. 2005a). Furthermore, the mouse antibodies to T21, SMA4, and TSC4 have all been shown to recognize a glycoprotein secreted in the distal caput or proximal corpus of the epididymis, which once released into the lumen, adsorbs to the sperm surface (Feuchter et al. 1987, Toshimori et al. 1988). The polyclonal antibody developed to FMS, in this report recognized an antigen of similar molecular mass, but all of our antibodies recognized the entire sperm surface. As sperm are known to vary in lipid and protein composition in their various surface segments, the different labeling patterns observed in earlier studies may stem from the inability of some monoclonal antibodies to identify an epitope of DEFB22 that is obscured by components of the surface
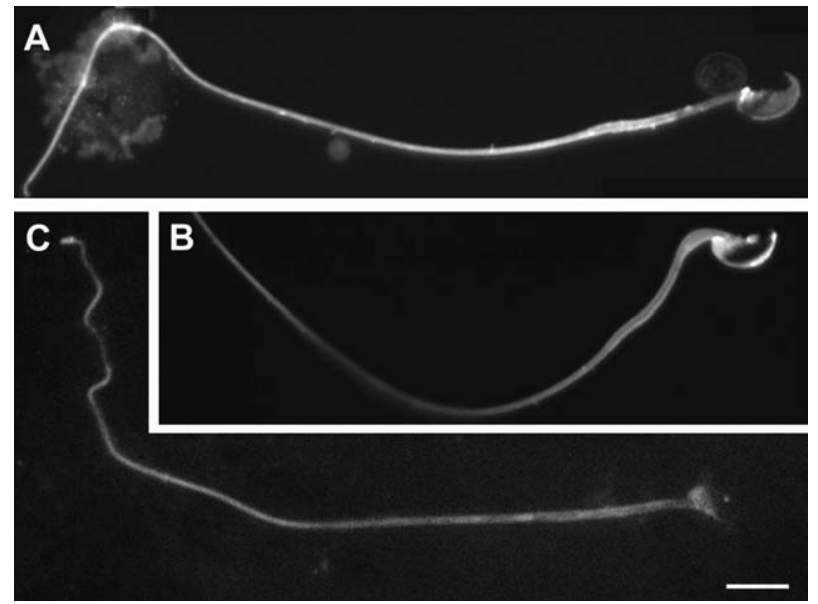

Figure 10 At $4 \mathrm{~h}$ after mating sperm found within the oviduct showed a variety of anti-FMS labeling patterns over the sperm head, but consistently the flagellum had a uniform label over the full length (A-C). Occasionally there was a lack of recognition over the equatorial segment (B) or over the entire acrosomal region (C). Bar $=10 \mu \mathrm{m}$. Preimmune controls showed no fluorescence (not shown). unique to the head region. Antibodies developed to mouse sperm DEFB22 peptide sequences also recognized a polypeptide of the same $130 / 54-57 \mathrm{kDa}$ molecular weight and labeled the entire mouse sperm surface; therefore, it is concluded that mouse sperm are similar to rat and monkey sperm in that the same $\beta$-defensin (126/22) may well serve as the most external sperm coating glycoprotein in primates and rodents.

The recent division of the mouse epididymis into ten genetically unique segments that are specialized to express maturation components (Johnston et al. 2005) is consistent with the reports of past researchers that placed the initial site of production as the distal caput (Vernon et al. 1982, Toshimori et al. 1988) or segments 5 and 6
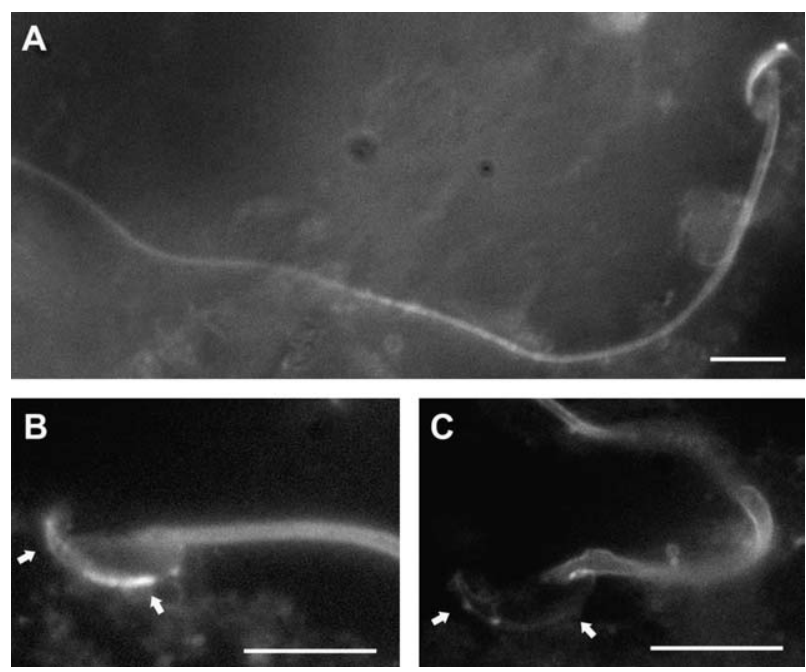

Figure 11 Mouse sperm had reached the oocyte-cumulus complex $4 \mathrm{~h}$ after mating and were found along the outer surface of the matrix (A and B) or partially embedded in the outer layer (C). Fertilization was not observed at $4 \mathrm{~h}$. The sperm found at the surface of the cumulus often had anti-FMS Ig (DEFB22) labeling over the posterior head and apical acrosomal region and covering the entire length of the flagellum (A and B). Sperm found embedded in the outer layer had anti-FMS Ig over the midpiece and flagellum, but little or no fluorescence was seen over the sperm head (C). Bar $=10 \mu \mathrm{m}$. 
with 6 being the initial corpus (Johnston et al. 2005). The results of the present investigation clearly show that DEFB22 is primarily expressed within the corpora epididymides where it is located along the stereocilia extending into the lumen and the vesicle-enriched region directly underlying the apical surface of the plasma membrane. DEFB22 is primarily expressed within a single region of the epididymis and then is readily absorbed to the sperm surface such that the lumen of the distal corpus is completely filled with labeled sperm, a situation similar to that described in rats (Rao et al. 2003). The real-time PCR clearly demonstrates that the highest level of mRNA expression is in the corpus and that there is little, if any, sign of DEFB22 production outside this narrow region of the epididymis.

In the present study, the FMS antibody and anti-DEFB22 did not recognize any rodent sperm other than mouse. Similarly, anti-rat DEFB22 did not recognize other rodent sperm such as mouse or hamster (Zanich et al. 2003). The homologues of DEFB22/126 must be rapidly evolving to a point that they have developed unique carbohydrate moieties, so that antibodies fail to recognize the same homologous glycoprotein in a closely related genus species. The DEFB22 peptide backbone is only about $17 \mathrm{kDa}$ in $\mathrm{MW}$, but the native protein has an apparent MW of $54-57 \mathrm{kDa}$. The difference in these molecular mass is thought to be due in large part to the extensive array of O-linked glycans bearing terminal sialic acids, which because of their negative charge, may function in sperm packaging and storage within the epididymis, as well as in forming a protective coat that is needed by sperm during residence in the female reproductive tract (Toshimori et al. 1990, 1991, Rao et al. 2003, Yudin et al. 2005b).

We have shown in the macaque sperm that as capacitation progresses, sperm loses DEFB126 over the head and that DEFB126 constitutes the vast majority of shed molecules at the time of capacitation (Tollner et al. 2004). The loss of DEFB126 is directly correlated with the acquisition of zona-recognition capability and its loss is required for sperm binding to the oviductal epithelium (Tollner et al. 2004, 2008a, 2008b). Like DEFB126, its mouse homologue DEFB22 is likely to be involved in capacitation and gamete recognition. In mouse sperm, a decapacitation factor that has garnered much attention is the phosphatidylethanolamine-binding protein 1 (PEBP1), which is released under capacitation-inducing conditions (Gibbons et al. 2005). PEBP1 is, in fact, a $23 \mathrm{kDa}$ GPI-anchored protein, which is the receptor for the decapacitation factor that can activate $\mathrm{Ca}^{++}$mobilization when released from the receptor (Fraser 1998, Gibbons et al. 2005, Moffit et al. 2007). Currently, the mechanism by which the $\beta$-defensin associate with the sperm plasma membrane is not known, but is believed that the initial $\beta$-defensin segment ( $n$-terminus) is linked/inserted into the outer leaflet, leaving the carboxyl region to extend into the surrounding milieu creating a glycocalyx shell around the sperm (Rao et al. 2003, Yudin et al. 2005a). Monoclonal antibodies T21, SMA4, and TSG4 may all recognize mouse DEFB22; the protein(s) they recognize have been proposed to be important for mouse sperm protection within the male and female reproductive tracts due to the surplus of sialic acids that are terminally positioned on the numerous $O$-linked glycocalyx sites (Feuchter et al. 1988, Toshimori et al. 1990).

Macaque sperm recovered from the uterus retain the DEFB126 coating, and it has been shown in vitro that DEFB126 contributes to sperm binding of the oviductal isthmus epithelial cells, potentially leading to the formation of a sperm reservoir in vivo (Tollner et al. $2008 a, 2008 b$ ). The loss of DEFB126 from the head of macaque sperm resulted in the loss of attachment of sperm to oviductal epithelia, suggesting that a release of DEFB126 from sperm in vivo may be associated with the detachment of sperm from isthmus cells and liberation from the oviductal reservoir (Tollner et al. 2008a, 2008b). In the present study, DEFB22 was shown to remain on mouse sperm in the uterus, oviduct, and oocyte-cumulus complex. In some oviductal sperm, as well as sperm within the cumulus matrix there was evidence that DEFB22 had been lost over the head, but not the tail, which is consistent with the series of events that have been proposed to take place in the primate oviduct. This phenomenon may also occur in rats, where DEFB22 is retained on the flagellum and eventually incorporated into the oolemma at fertilization (Gaunt 1983).

The importance of retaining DEFB22 on the flagellum is not clear. In the macaque, the sperm initiate and maintain binding to oviductal epithelial cells via the head (Tollner et al. 2008a, 2008b). DEFB126-mediated attachment appears to be facilitated by wedging of the sperm head into spaces between neighboring epithelial cells (Tollner et al. 2008a, 2008b). The flagella of motile sperm, on the other hand, do not appear to maintain contact with epithelial cells although we have observed that the flagella of dead and non-motile cells will attach to epithelial surfaces. We speculate that the greater surface area of the head, combined with its tapered, paddle-like shape, aids sperm in the attachment to oviductal epithelium. In contrast, motility of the flagellum probably overcomes what is likely a lower binding avidity due to fewer points of contact with the epithelial surface.

The $\beta$-defensins are abundantly expressed throughout the epididymis and vas deferens and likely form the backbone of innate immune protection, which is thought to be especially critical because of the absence of adaptive immune protection in this region (Patil et al. 2005). While a broad spectrum of these cationic peptides are expressed, only a few (DEFB22/DEFB126, DEFB118, and DEFB132) have been shown to be integrated into the sperm surface (Liu et al. 2001, Yudin et al. 2003, Oh et al. 2006, Lin et al. 2008). It is clear that both DEFB22 and DEFB126 are applied to the entire sperm surface in the corpus epididymis and 
retained on the sperm up to the time they reach the oviduct and their ultimate goal, the oocyte (Gaunt 1983, Jones et al. 1985, Zanich et al. 2003).

Given the presence of DEFB22 on rodent sperm and DEFB126 on primate sperm, we speculate that this glycoprotein may be the most external coat on most if not all mammalian sperm and that it has a common critical role in the establishment of a barrier between sperm and the external environment. We and others have provided evidence that the DEFB126/DEFB22 glycoprotein is functionally important for 1 ) storage within the caudal epididymis, 2) protection from enzymatic attack, 3) protection from immunorecognition in the female, 4) regulation of the capacitation process, 5) creation of a sperm reservoir in the oviduct, and 6) anti-microbial protection. (Feuchter et al. 1988, Toshimori et al. 1991, Li et al. 2001, Rao et al. 2003, Tollner et al. 2004, 2008a, $2008 b$, Yudin et al. 2005a). Further investigation of this critical sperm component is clearly warranted.

\section{Materials and Methods \\ Reagents}

All chemicals and reagents were purchased from SigmaAldrich Chemical Co., unless otherwise specified.

\section{Animals}

Adult male and female BDF-1 (strain B6D2F1) mice were obtained from Charles River Laboratories (Wilmington, MA, USA). All mice were 14 weeks old at the time of purchase and most were used experimentally prior to 28 weeks of age. All mice were subjected to a reverse light cycle, in which $0600 \mathrm{~h}$ to $1800 \mathrm{~h}$ was dark. Mice were housed in standard plastic cages (two to three per cage) and fed a standard Purina mouse laboratory diet with water given ad libitum in compliance with American Association of Accreditation of Laboratory Animal Care Standards. At the time of experimentation, mice were exposed to $100 \% \mathrm{CO}_{2}$ for 10 min before cervical dislocation. All methods and procedures with animal subjects were approved by the Institutional Animal Care and Use Committee (IACUC) at the University of California, Davis, CA, USA.

All of the rabbit injection procedures were pre-approved by the Research Animal Care Committee, which strictly adheres to the Guide for the Care and Use of Laboratory Animals.

\section{Mating}

After a week of reversed light cycles, females were placed with breeding males to check for signs of lordosis about 4-5 $\mathrm{h}$ after the initiation of the dark cycle $(0600 \mathrm{~h})$. Following initial observation of copulation, females were left with the male for $1 \mathrm{~h}$ and then killed at $4 \mathrm{~h}$ following the initial time of copulation. The sperm were recovered from the uterus by gently milking or expelling the contents with tweezers, such that the uterine fluid matrix was released into a Dulbecco's PBS (DPBS)-filled Petri dish.

\section{Antibody production}

The cauda epididymidis and vas deferens of 14- to 20-week-old male mice were excised and placed into a protein-free, defined Tyrode's mouse medium at $37^{\circ} \mathrm{C}$ (Wolf et al. 1976). The sperm were gently extruded from the vas deferens with forceps and pipetted into the fresh medium. The cauda epididymidis was perforated with fine-tipped forceps and the sperm were allowed to swim out for $10-20 \mathrm{~min}$ at $37^{\circ} \mathrm{C}$. Both the caudal and vas deferens sperm $(500 \mu \mathrm{l})$ were layered over a $40 \%$ Percoll solution $(800 \mu \mathrm{l})$ and centrifuged for $10 \mathrm{~min}$ at $300 \mathrm{~g}$. The pelleted sperm were washed in fresh medium at room temperature (RT) by centrifugation at $300 \mathrm{~g}$ for $5 \mathrm{~min}$. The washed sperm were immediately resuspended in $3.2 \%$ paraformaldehyde $/ 0.125 \%$ glutaraldehyde in DPBS. After overnight fixation at $4{ }^{\circ} \mathrm{C}$ the sperm were washed thoroughly $(4 \times)$ by centrifugation in fresh DPBS. The initial immunization was accomplished with $10^{6}$ sperm that had been suspended in Freund's adjuvant. The sperm from two different mice were combined for each rabbit injection. Two rabbits received injections of fixed cauda sperm and two rabbits received injections of fixed vas deferens sperm. Boost injections with whole fixed sperm combined with Freunds incomplete adjuvant were given on days 30 and 50 . Rabbits bled on days 60 and 75 . The antibodies developed from whole fixed sperm will be referred to as FMS.

A peptide antibody was developed in cooperation with YenZym Antibodies (Burlingame, CA, USA). The peptides were a 19 mer peptide and a 14 mer peptide derived from the protein sequence for the $\beta$-defensin 22 (Mm.99065/AK078980) found in mice. The two regions were amino acids 39-52 (RDGEKQTEPATSKC-) and 72-89 (-CGGQNSDNLVTAGGDEGSS). Prior to injection for production of an antibody specific to $\beta$-defensin 22, both peptides were conjugated to Keyhole Limpet Hemocyanin (KLH) using the added terminal cysteine. Antibody titers were monitored for each peptide and the sera from all of the rabbits were collected 84 days after the initial immunization. Ig was purified from the serum with ammonium sulfate precipitation and resuspended in DPBS and dialyzed overnight in DPBS.

\section{Purification and identification of DEFB22}

Cauda epididymidis and vas deferens were isolated from 16- to 20-week-old males and the sperm were released by gentle extraction into previously described medium, in which BSA $(2.6 \mathrm{mg} / \mathrm{ml})$ was added. The sperm were removed from the minced tissue and layered over a $40 \%$ Percoll suspension. The sample was microfuged for $5 \mathrm{~min}$ at $600 \mathrm{~g}$ and the resulting pellet was washed $(2 \times$ at $300 \mathrm{~g})$ with fresh medium. Purified FMS-Ig was added to sperm $\left(10^{7} / \mathrm{ml}\right)$ such that the sperm did not agglutinate $(100 \mu \mathrm{g} / \mathrm{ml})$, and incubated for $1 \mathrm{~h}$ at $37^{\circ} \mathrm{C}$. The sperm were washed $(2 \times$ at $300 \mathrm{~g})$ with BSA-free buffer and the resulting pellet was resuspended in extraction buffer $(25 \mathrm{mM}$ $\mathrm{NaCl}, 5 \mathrm{mM} \mathrm{KCl}, 2 \mathrm{mM}$ HEPES, $10 \mathrm{mM}$ n-octyl $\beta$-D-glucopyranoside, $1 \%$ Brijj, $0.1 \%$ Triton $X-100$, and protease inhibitor 1 cocktail: EMB Biosciences, Lajolla, CA, USA).The $\mathrm{pH}$ was adjusted to 7.3 and maintained at $4{ }^{\circ} \mathrm{C}$ for $2 \mathrm{~h}$ with constant agitation. The sample was centrifuged $(1000 \mathrm{~g})$ for $10 \mathrm{~min}$ 
before filtering through a $0.22 \mu \mathrm{m}$ syringe filter. Washed Protein A (3.5 mg)-linked agarose beads were resuspended in extraction buffer overnight and washed $(2 \times)$ before mixing with the sperm-extraction buffer for $2 \mathrm{~h}$ with continual rolling at $4{ }^{\circ} \mathrm{C}$. The Protein $\mathrm{A}$ beads were washed $(5 \times)$ with fresh cold $\left(4{ }^{\circ} \mathrm{C}\right)$ medium over a 2 - $\mathrm{h}$ period. The washed beads were resuspended in low ionic strength, high $\mathrm{pH}$ elution buffer (25 mM NaCl and $8 \mathrm{mM} \mathrm{NaHPO}_{4}, \mathrm{pH} 10$ ) for $1 \mathrm{~h}$ and the supernatant was concentrated with a Centricon $10 \mathrm{NMWL}$ (Millipore, Billerica, MA, USA) and mixed with a 1:4 solution of SDS solubilizing buffer (Pierce, Rockford, IL, USA).

\section{Histology and immunolabeling}

Reproductive tissue from killed male mice were excised and immediately placed in 3.2\% paraformaldehyde in DPBS. After $24 \mathrm{~h}$ at $4{ }^{\circ} \mathrm{C}$ the samples were exchanged with fresh fixative for an additional $24 \mathrm{~h}$. The samples were dehydrated through a graded ethanol series, cleared in toluene, and embedded in Paraplast. Sections of the tissue were cut at $6 \mu \mathrm{m}$ and mounted on clean glass slides. After mounting, the tissue slices were deparaffinized $2 \times$ in xylene, followed by a four-step rehydration from $100 \%$ ethanol to water. Rehydrated tissue slices were then stained with Papanicolaou stain (Fisher, Pittsburg, PA, USA) or transferred into DPBS/1\%BSA. The sections were blocked for $30 \mathrm{~min}$ before being exposed to a 1:200 dilution of specific antibody:block. Exposure to the primary antibody, both preimmune and immune, was carried out at RT for $1 \mathrm{~h}$, and then the slides were thoroughly washed by dipping through a series of DPBS washes and returned to blocking solution. Recognition of the labeled antigen was accomplished using the VECTASTAIN ABC-AP procedure (Vector Laboratories, Burlingame, CA, USA). Visualization of the goat anti-rabbit-linked enzyme marker, alkaline phosphatase (AP), was achieved with BCIP/NBT (Pierce) as the reaction product. The reaction was stopped with $10 \mathrm{mM}$ EDTA $(2 \times$ washes) and then the slides were dehydrated and cleared with xylene before mounting with Protexx medium (Baxter Diagnostics, Deerfield, IL, USA) as the cover slip was applied.

\section{RNA isolation and CDNA synthesis}

Five different tissues of the male reproductive tract (testis, caput, corpus, cauda, and vas deferens) were carefully dissected and samples from each were pooled from three BDF-1 mice. Pooled tissue samples $(0.02-0.1 \mathrm{~g})$ were homogenized by ultrasonification in a guanidine thiocyanate buffer, and the RNA was isolated by ultracentrifugation over a cesium chloride gradient as described (Chirgwin et al. 1979, Jones \& Bevins 1992, Mallow et al. 1996). Isolated total RNA was quantified in duplicate by u.v. absorbance at $260 \mathrm{~nm}$ using a spectrophotometer (Nanodrop ND-1000 Wilmington, DE,
USA). To synthesize cDNA, $0.5-1.0 \mu \mathrm{g}$ of total RNA was reverse transcribed with SuperScript II reverse transcriptase (50 units) using an oligo-(dT) 12-18 primer according to the supplier's protocol (Invitrogen). After RT, the reaction product was treated with RNase-H (two units; Wehkamp et al. 2006). The tissue-specific cDNA was then purified using column absorption chromatography (Qiagen) and the eluate was diluted to an equivalent of $10 \mathrm{ng} / \mathrm{ul}$ in $10 \mathrm{mM}$ Tris-HCL $(\mathrm{pH}$ 8.5) based on the initial input concentration of total RNA.

\section{Cloning of gene-specific plasmids}

Partial-length cDNAs encoding Defb22 and $\beta$-actin were cloned from mouse epididymis tissue by RT-PCR. For Defb22, genespecific primers (Table 1) were used in a standard PCR and the cDNA product was cloned into Bluescript II $+\mathrm{s} / \mathrm{k}$ plasmid (Stragagene, La Jolla, CA, USA) according to the standard procedures (Jones \& Bevins 1992, Mallow et al. 1996). For $\beta$-actin, a 3'-RACE protocol was used as described (Mallow et al. 1996). Briefly, $2 \mu \mathrm{g}$ of total RNA from mouse epididymis was reverse transcribed using the $\mathrm{RACE} /$ anchor primer $5^{\prime}$-TTCTAGAATTCAGCGGCCGC(T) ${ }_{30} \mathrm{VN}-3^{\prime}$ (Wehkamp et al. 2006). The resulting CDNA product was used as a template in a PCR using the gene-specific and antisense RACE primers (Table 1). The identity of each plasmid was confirmed by direct DNA sequence analysis. The plasmids were quantified by spectrophotometric absorbance at $260 \mathrm{~nm}$, and then serially diluted using yeast RNA $(0.2 \mu \mathrm{g} / \mu \mathrm{l}$ as a carrier nucleic acid for all dilutions). These diluted plasmid solutions were used as a template in quantitative real-time PCR to generate standard curves for absolute quantification as described (Wehkamp et al. 2006).

\section{Quantitative real-time PCR analysis}

Gene-specific real-time PCR primers (Table 1) were selected using MacVector software (MacVector Inc., Cary, NC, USA), and purchased from Invitrogen. Real-time PCR was performed using the reproductive tissue-specific cDNA as a template with specific oligonucleotide primer pairs as described previously (Wehkamp et al. 2006). Each $1 \mu \mathrm{l} \mathrm{PCR}$ contained $4 \mathrm{mM} \mathrm{MgC12,} 0.5 \mu \mathrm{g}$ of each gene-specific primer (Table 1) and $1 \times$ LightCycler-Fast Start DNA Master SYBR Green I mis (Roche Diagnostics). The qRT-PCR was performed using the LightCycler 2.0 system (Roche Diagnostics). A no-template reaction was included as a negative control for each qRT-PCR experiment, and gene-specific plasmid standards were included with every set of reactions both as a positive control and for absolute quantification purposes. The PCR cycling times and temperatures, and methods of data analysis were as described previously (Wehkamp et al. 2006). All samples were analyzed in duplicate, and variation between duplicates was $<10 \%$ for every reported value.

Table 1 Oligonucleotide primer sequences used in qRT-PCR.

\begin{tabular}{|c|c|c|}
\hline Gene product & Sense & Antisense \\
\hline DEFB22 & $\begin{array}{l}\text { Cloning 5'-GAACCTACTGCCTACTGACAGGAGCC-3' } \\
\text { qPCR 5' CCCATTTGGTCACAGGTGGCTG } 3^{\prime}\end{array}$ & $\begin{array}{l}\text { Cloning 5'-CCTCTTGGCTTTTTTCAACCAGGGAT-3' } \\
\text { qPCR 5'-AGGTTCCGTCTGCTTCTCCCCG-3' }\end{array}$ \\
\hline$\beta$-actin & $\begin{array}{l}\text { Cloning 5'-TGATGGTGGGCATGGGTCAG-3' } \\
\text { qPCR 5'-GCTGAGAGGGAAATCGTGCGTG-3' }\end{array}$ & 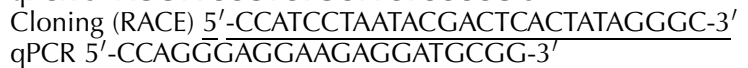 \\
\hline
\end{tabular}




\section{Fine structure and immunolabeling}

The caput and corpus regions of the mouse epididymis were excised and immersed in $2.5 \%$ glutaraldehyde/3.2\% paraformaldehyde in $0.2 \mathrm{M}$ cacodylate $(\mathrm{pH} 7.4)$ at $4{ }^{\circ} \mathrm{C}$ for $2 \mathrm{~h}$. The samples were washed in $0.2 \mathrm{M}$ cacodylate for $2 \mathrm{~h}(2 \times)$ and placed into $2 \%$ osmium tetroxide in $0.1 \mathrm{M}$ cacodylate for $2 \mathrm{~h}$. After postfixation, the samples were dehydrated in a graded alcohol series $50-100 \%$ over a 4 -h period. After remaining in fresh $100 \%$ ethanol for $1 \mathrm{~h}$ the sample was further dehydrated in $100 \%$ acetone. The dehydrated tissue samples were infiltrated in Spurrs epoxy (Ted Pella, Redding, CA, USA) and embedded in an eponaraldite mixture. Sections were cut with a diamond knife and stained with uranyl acetate and lead citrate. Immunogold labeling was carried out with the sperm that were collected from the cauda epididymidis or the vas deferens. The sperm were fixed with $3.2 \%$ paraformaldehyde and $0.125 \%$ glutaraldehyde for $2 \mathrm{~h}$ and extensively $(4 \times)$ washed with blocking solution as described for fluorescent labeling. After washing, the sperm were incubated with anti-FMS Ig that was at a final concentration of $50 \mu \mathrm{g} / \mathrm{ml}$ in blocking solution and rolled for $2 \mathrm{~h}$. Preimmune serum was substituted for anti-FMS Ig and used as the control. After washing by continuously rolling the sample for $2-3 \mathrm{~h}$ in at least four changes of blocking solution, the sperm were resuspended in goat anti-rabbit Ig ( $5 \mu \mathrm{g} / \mathrm{ml}$ ) linked to $15 \mathrm{~nm}$ gold (EY Laboratories, San Mateo, CA, USA). The sperm were again washed thoroughly and processed for transmission electron microscopy (TEM) as previously discussed. All photographs were taken on a Philips 401 TEM (Eindhoven, The Netherlands).

\section{Electrophoresis and western blot analysis}

All gels used were $8-16 \%$ Tris-glycine (Invitrogen). The sperm were solubilized in SDS-buffer (Pierce) at $60{ }^{\circ} \mathrm{C}$ for $5 \mathrm{~min}$, centrifuged, and the pellet was discarded. The soluble fraction was filtered $22 \mu \mathrm{m}$ ) and chemically reduced with $100 \mathrm{mM}$ of dithiolthreitol (DTT) and returned to $60{ }^{\circ} \mathrm{C}$ for $5 \mathrm{~min}$. All of the tissue samples were solubilized similarly, but the tissue was first shredded prior to incubation with SDS buffer. All of the samples were run electrophoretically and stained with GelCode Blue (Pierce) to find the appropriate concentration for electroblotting to nitrocellulose membranes. $6-8 \mu \mathrm{g} /$ well was applied for both electrophoresis and western blotting. After the gels were transferred to nitrocellulose membrane they were blocked in 2\% BSA, 2\% nonfat dry milk (BioRad), and $2 \%$ fish gelatin, which were all added to TBS $(50 \mathrm{mM}$ Tris- $\mathrm{HCl}, \mathrm{pH}$ 7.4 , with $0.3 \mathrm{M} \mathrm{NaCl}$ and $0.1 \%$ polyoxyethylene sorbitan monolaurate; Tween 20). Blots were incubated with the primary antibody ( $50 \mu \mathrm{g} / 10 \mathrm{ml}$ of blocking solution), purified from each of the immunized rabbits and agitated for at least $2 \mathrm{~h}$ before washing in TBS for at least $30 \mathrm{~min}$. Control blots of solubilized mouse sperm were incubated with preimmune primary $(50 \mu \mathrm{g} / 10 \mathrm{ml}$ of blocking solution) antibodies purified from serum collected from rabbits prior to immunization with either FMS or $\beta$-defensin 22 peptide. Other control blots were incubated with a mixture of the $\beta$-defensin 22 peptides (YenZym, Billerica, CA, USA) and serum from peptideimmunized rabbits $(10 \mu \mathrm{g}$ of each peptide/10 $\mu \mathrm{g}$ of serum). Blots were then incubated in secondary antibody (1:2000 goat anti-rabbit) that had been coupled to AP (BioRad). The blots were incubated for $1 \mathrm{~h}$ in the secondary antibody and then washed for at least $3 \times / 10 \mathrm{~min}$ in TBS. After washing, the blots were placed in AP substrate (1-Step NBT-BCIP; Pierce) and continuously swirled until the bands were detected.

\section{Immunofluorescence/photomicrography}

Sperm were fixed in 2\% paraformaldehyde/0.125\% glutaraldehyde in DPBS for at least $1 \mathrm{~h}$ before washing thoroughly in a blocking solution of $1 \%$ BSA in DPBS. The sperm were incubated in anti-DEFB22, anti-FMS, or preimmune serum, each diluted in blocking solution at 1:250. The samples were co-incubated for $1-2 \mathrm{~h}$ and washed $(2-3 \times)$ before incubation in a $20 \mathrm{~g} / \mathrm{ml}$ goat anti-rabbit Alexa 488 blocking solution. The samples were washed in blocking solution before resuspending in a fluorescent stabilization medium (50\% glycerol, $0.2 \%$ $\mathrm{NaN}_{3}, 1 \%$ paraformaldehyde/DPBS). Images were taken with a cooled CCD digital camera (Magnafire; Optronics, Santa Barbara, CA, USA) mounted on either a Leitz Labolux microscope (Carl Zeiss Vision, Hamburg, Germany) or an Olympus BH-2 (Olympus Scientific, Tokyo, Japan). The Leitz Labolux was equipped with a $200 \mathrm{~W}$ mercury fluorescence vertical illuminator and $\alpha-1-\lambda$ Ploemopac incident light fluorescence vertical illuminator employing an 13 filter cube, having a BP450-490 excitation filter, a RKP 0510 dichromatic mirror and a LP515 suppression filter. Images were captured using Magnafire 2.0 software (Optronics) and processed with Adobe Photoshop (Adobe Systems, San Jose, CA, USA) for production of figures.

\section{Declaration of interest}

There were no conflicts of interest that would prejudice its impartiality.

\section{Funding}

The study was paid for out of departmental funds.

\section{Acknowledgements}

This manuscript is Bodega Marine Laboratory Contribution number 2431.

\section{References}

Bedford J 1975 Maturation, transport and fate of spermatozoa in the epididymis. In Handbook of Physiology, Endocrinology, vol 5, pp 303-317. Ed S Greiger. Washington DC: American Physiological Society.

Bedford J 1990 Sperm dynamics in the epididymis. In Gamete Physiology, pp 53-67. Eds RA Asch, JP Balmaceda \& I Johnston. Norwell, MA: Serono Symposia.

Bedford J \& Hoskins D 1990 The mammalian spermatozoa: morphology, biochemistry, and physiology. In Marshall's Physiology of Reproduction, vol 2, pp 379-568. Ed G Lamming. Edinburgh: Churchill Livingston.

Chang MC \& Pincus G 1951 Physiology of fertilization in mammals. Physiological Reviews 31 1-26. 
Chirgwin JM, Przybyla AE, MacDonald RJ \& Rutter WJ 1979 Isolation of biologically active ribonucleic acid from sources enriched in ribonuclease. Biochemistry 18 5294-5299.

Cooper TG 1986 The epididymis, sperm maturation and fertilization. In Spermatogenesis, Fertilization, Contraception, Eds E Nieschlag \& UF Habernicht. Berlin/New York: Springer-Verlag.

Cooper TG 1998 Interactions between epididymal secretions and spermatozoa. Journal of Reproduction and Fertility 53 119-136.

Dacheux JL, Gatti JL \& Dacheux F 2003 Contribution of epididymal secretory proteins for spermatozoa maturation. Microscopy Research and Technique 61 7-17.

Feuchter FA, Vernon RB \& Eddy EM 1981 Analysis of the sperm surface with monoclonal antibodies: topographically restricted antigens appearing in the epididymis. Biology of Reproduction 24 1099-1110.

Feuchter FA, Green MF \& Tabet AJ 1987 Maturation antigen of the mouse sperm flagellum: II. Origin from holocrine cells of the distal caput epididymis. Anatomical Record 217 146-152.

Feuchter FA, Tabet AJ \& Green MF 1988 Maturation antigen of the mouse sperm flagellum: I. Analysis of its secretion, association with sperm, and function. American Journal of Anatomy 181 67-76.

Fraser LR 1998 Interactions between a decapacitation factor and mouse spermatozoa appear to involve fucose residues and a GPI-anchored receptor. Molecular Reproduction and Development 51 193-202.

Gaunt SJ 1983 Spreading of a sperm surface antigen within the plasma membrane of the egg after fertilization in the rat. Journal of Embryology and Experimental Morphology 75 259-270.

Gibbons R, Adeoya-Osiguwa SA \& Fraser LR 2005 A mouse sperm decapacitation factor receptor is phosphatidylethanolamine-binding protein 1. Reproduction 130 497-508.

Harrison RA 1996 Capacitation mechanisms, and the role of capacitation as seen in eutherian mammals. Reproduction, Fertility, and Development 8 581-594.

Hinton BT \& Palladino MA 1995 Epididymal epithelium: its contribution to the formation of a luminal fluid microenvironment. Microscopy Research and Technique 30 67-81.

Hinton BT, Palladino MA, Rudolph D, Lan ZJ \& Labus JC 1996 The role of the epididymis in the protection of spermatozoa. Current Topics in Developmental Biology 33 61-102.

Jaiswal BS \& Eisenbach M 2002 Capacitation. In Fertilization, pp 57-117. Ed. DM Hardy. San Diego: Academic Press.

Johnston DS, Jelinsky SA, Bang HJ, DiCandeloro P, Wilson E, Kopf GS \& Turner TT 2005 The mouse epididymal transcriptome: transcriptional profiling of segmental gene expression in the epididymis. Biology of Reproduction 73 404-413.

Johnston DS, Turner TT, Finger JN, Owtscharuk TL, Kopf GS \& Jelinsky SA 2007 Identification of epididymis-specific transcripts in the mouse and rat by transcriptional profiling. Asian Journal of Andrology 9 522-527.

Jones RC 1998 Evolution of the vertebrate epididymis. Journal of Reproduction and Fertility 53 163-181.

Jones RC 1999 To store or mature spermatozoa? The primary role of the epididymis. International Journal of Andrology 22 57-67.

Jones DE \& Bevins CL 1992 Paneth cells of the human small intestine express an antimicrobial peptide gene. Journal of Biological Chemistry $26723216-23225$.

Jones R, Brown CR, von Glos KI \& Gaunt SJ 1985 Development of a maturation antigen on the plasma membrane of rat spermatozoa in the epididymis and its fate during fertilization. Experimental Cell Research $15631-44$.

Li P, Chan HC, He B, So SC, Chung YW, Shang Q, Zhang YD \& Zhang YL 2001 An antimicrobial peptide gene found in the male reproductive system of rats. Science 291 1783-1785.

Lin YQ, Li JY, Wang HY, Liu J, Zhang CL, Wang WT, Liu J, Li N \& Jin SH 2008 Cloning and identification of a novel sperm binding protein, HEL75 , with antibacterial activity and expressed in the human epididymis. Human Reproduction 23 2086-2094.

Liu Q, Hamil KG, Sivashanmugam P, Grossman G, Soundararajan R, Rao AJ, Richardson RT, Zhang YL, O'Rand MG, Petrusz P et al. 2001 Primate epididymis-specific proteins: characterization of ESC42, a novel protein containing a trefoil-like motif in monkey and human. Endocrinology 142 4529-4539.
Lopo AC \& Vacquier VD 1980 Sperm-specific surface antigenicity common to seven animal phyla. Nature 288 397-399.

Mallow EB, Harris A, Salzman N, Russell JP, DeBerardinis RJ, Ruchelli E \& Bevins CL 1996 Human enteric defensins. Gene structure and developmental expression. Journal of Biological Chemistry 271 4038-4045.

Moffit JS, Boekelheide K, Sedivy JM \& Klysik J 2007 Mice lacking Raf kinase inhibitor protein-1 (RKIP-1) have altered sperm capacitation and reduced reproduction rates with a normal response to testicular injury. Journal of Andrology 28 883-890.

Moore HD 1998 Contribution of epididymal factors to sperm maturation and storage. Andrologia 30 233-239.

Oh J, Lee J, Woo JM, Choi E, Park I, Han C, Baek N, Lee H, Kim do H \& Cho C 2006 Systematic identification and integrative analysis of novel genes expressed specifically or predominantly in mouse epididymis. BMC Genomics 7314.

Okabe M, Takada K, Adachi T, Kohama Y, Mimura T \& Aonuma S 1986 Studies on sperm capacitation using monoclonal anti-body - disappearance of an antigen from the anterior part of mouse sperm head. Journal of Pharmacobio-Dynamics 9 55-60.

Okabe M, Adachi T, Takada K, Oda H, Yagasaki M, Kohama Y \& Mimura T 1987 Capacitation-related changes in antigen distribution on mouse sperm heads and its relation to fertilization rate in vitro. Journal of Reproductive Immunology 11 91-100.

Patil AA, Cai Y, Sang Y, Blecha F \& Zhang G 2005 Cross-species analysis of the mammalian beta-defensin gene family: presence of syntenic gene clusters and preferential expression in the male reproductive tract. Physiological Genomics 23 5-17.

Piko L 1969 Gamete structure and sperm entry in mammals. In Fertilization, vol 2, pp 325-403. Eds C Metz and A Monroy. New York: Academic Press.

Rao J, Herr JC, Reddi PP, Wolkowicz MJ, Bush LA, Sherman NE, Black M \& Flickinger CJ 2003 Cloning and characterization of a novel spermassociated isoantigen (E-3) with defensin- and lectin-like motifs expressed in rat epididymis. Biology of Reproduction 68 290-301.

Schroter S, Osterhoff C, McArdle W \& Ivell R 1999 The glycocalyx of the sperm surface. Human Reproduction Update 5 302-313.

Tollner TL, Yudin AI, Treece CA, Overstreet JW \& Cherr GN 2004 Macaque sperm release ESP13.2 and PSP94 during capacitation: the absence of ESP13.2 is linked to sperm-zona recognition and binding. Molecular Reproduction and Development 69 325-337.

Tollner TL, Yudin AI, Tarantal AF, Treece CA, Overstreet JW \& Cherr GN 2008 a Beta-defensin 126 on the surface of macaque sperm mediates attachment of sperm to oviductal epithelia. Biology of Reproduction $\mathbf{7 8}$ 400-412.

Tollner TL, Yudin Al, Treece CA, Overstreet JW \& Cherr GN $2008 b$ Macaque sperm coating protein DEFB126 facilitates sperm penetration of cervical mucus. Human Reproduction 23 2523-2534.

Toshimori K, Araki S \& Oura C 1988 Masking of sperm maturation antigen by sialic acid in the epididymis of the mouse. An immunohistochemical study. Histochemistry 90 195-200.

Toshimori K, Araki S \& Oura C 1990 Cryptodeterminant of a sperm maturation antigen on the mouse flagellar surface. Biology of Reproduction 42 151-160.

Toshimori K, Araki S, Oura C \& Eddy EM 1991 Loss of sperm surface sialic acid induces phagocytosis: an assay with a monoclonal antibody T21, which recognizes a 54K sialoglycoprotein. Archives of Andrology 27 79-86.

Turner TT 1995 On the epididymis and its role in the development of the fertile ejaculate. Journal of Andrology 16 292-298.

Vernon RB, Muller CH, Herr JC, Feuchter FA \& Eddy EM 1982 Epididymal secretion of a mouse sperm surface component recognized by a monoclonal antibody. Biology of Reproduction 26 523-535.

Wehkamp J, Chu H, Shen B, Feathers RW, Kays RJ, Lee SK \& Bevins CL 2006 Paneth cell antimicrobial peptides: topographical distribution and quantification in human gastrointestinal tissues. FEBS Letters $\mathbf{5 8 0}$ 5344-5350.

Wolf DP, Inoue M \& Stark RA 1976 Penetration of zona-free mouse ova. Biology of Reproduction 15 213-221.

Yanagimachi R 1994 Mammalian fertilization. In The Physiology of Reproduction, pp 189-317. Eds E Knobil \& JD Neill. New York: Raven Press. 
Yudin Al, Tollner TL, Li MW, Treece CA, Overstreet JW \& Cherr GN 2003 ESP13.2, a member of the beta-defensin family, is a macaque sperm surface-coating protein involved in the capacitation process. Biology of Reproduction 69 1118-1128.

Yudin AI, Generao SE, Tollner TL, Treece CA, Overstreet JW \& Cherr GN 2005a Beta-defensin 126 on the cell surface protects sperm from immunorecognition and binding of anti-sperm antibodies. Biology of Reproduction 73 1243-1252.

Yudin AI, Treece CA, Tollner TL, Overstreet JW \& Cherr GN 2005b The carbohydrate structure of DEFB126, the major component of the cynomolgus Macaque sperm plasma membrane glycocalyx. Journal of Membrane Biology 207 119-129.
Zanich A, Pascall JC \& Jones R 2003 Secreted epididymal glycoprotein 2D6 that binds to the sperm's plasma membrane is a member of the beta-defensin superfamily of pore-forming glycopeptides. Biology of Reproduction 69 1831-1842.

Received 16 April 2008

First decision 7 May 2008

Revised manuscript received 25 August 2008

Accepted 11 September 2008 